\title{
REGENERAÇÃO DE BROTAÇÕES DE MACIEIRA (Malus domestica, Borkh.) cv. GALA ${ }^{1}$
}

\author{
MÁRCIA WULFF SCHUCH ${ }^{2}$, JOSÉ ANTONIO PETERS ${ }^{3}$
}

\begin{abstract}
RESUMO. Por meio deste trabalho, foi desenvolvido um protocolo de regeneração de brotações em explantes de macieira, cultivar Gala, visando a sua utilização em programas de transformação genética. Para tanto, testaram-se diferentes tipos de explante (folha escarificada, segmento foliar e entrenós), em diferentes meios de cultura, com Benzilaminopurina (BAP) e Thidiazuron (TDZ), em concentrações de $0 ; 3,0 ; 4,0$ e 5,0mg.L $\mathrm{L}^{-1}$, e a exposição ou não das brotações, de onde foram retirados os explantes, a uma semana de escuro antes da retirada dos mesmos. As variáveis avaliadas foram percentagem de explantes regenerados, número de brotações por explante e presença de vitrificação. Concluiu-se que a folha escarificada e os segmentos foliares foram os melhores tipos de explantes; a colocação das brotações no escuro durante uma semana aumentou a taxa de regeneração e o número de brotações e diminuiu a necessidade de BAP para formar o mesmo número de brotações do que naqueles mantidos na luz; as melhores concentrações de BAP foram de 4,0 a 5,0mg.L-1 e o TDZ, nas maiores concentrações, causou vitrificação.
\end{abstract}

Termos para indexação: morfogênese, reguladores de crescimento, BAP, TDZ

\section{REGENERATION OF APPLE SHOOTS (Malus domestica, Borkh.) cv. GALA}

\begin{abstract}
The main objective of this work was to develop regeneration protocol in order to produce transgenics cv. "Gala" plants. In the regeneration studies, different explant sources were evaluated (wounded leaf; leaf segments; internodes) in different culture media containing BAP and TDZ $\left(0 ; 3,0 ; 4,0\right.$ and 5,0mg. $\left.\mathrm{L}^{-1}\right)$, and the effect of the darkness in the explant source, were also analised in the frequencies and number of regenerate shoots. The wounded leaf and leaf segments shown the best response. Pre-conditioning the explants source during a week in darkness conditions increased the regeneration rates and the number of shoots, decreasing the optimum level of BAP necessary to obtain the same number of shoots. BAP at 4,0 or 5,0mg. $\mathrm{L}^{-1}$ showed better responses however, higher TDZ concentrations promoted vitrification.
\end{abstract}

Index terms: morfogenesis, growth regulators, BAP, TDZ

\section{INTRODUÇÃO}

No melhoramento genético de fruteiras de clima temperado, geralmente são utilizados os métodos tradicionais, onde os programas podem durar anos até que se produza uma cultivar geneticamente estável. A transformação genética proporciona a introdução de gene correspondente a alguma característica benéfica dentro do genoma de uma cultivar comercial estabelecida, proporcionando, desta forma, a aceleração do processo de melhoramento . Espécie de clima temperado que ocupa lugar de destaque, como a macieira cultivar Gala, pode ser melhorada através de engenharia genética.

Para a aplicação das técnicas de transformação de plantas, é necessário que as células ou tecidos transformados sejam regenerados em plantas que expressem o gene introduzido. Desta forma, a eficiência do sistema de cultura de tecidos in vitro é indispensável quando se quer fazer melhoramento de plantas pela transformação genética. A eficiência na cultura dos tecidos depende do controle da morfogênese, a qual é influenciada por vários fatores como espécie, cultivar, tipo de explante, componentes nutricionais do meio, reguladores de crescimento e ambiente de cultura (Rao et al., 1996).

Em macieira, a utilização da transformação genética é limitada pela dificuldade de regeneração de seus explantes e pela baixa eficiência na transformação. A organogênese direta é o sistema mais adequado, porém é mais difícil de se obter in vitro, para a regeneração de células transformadas, pois, segundo Tzifira et al. (1997), evita a formação de escapes e diminui a possibilidade de ocorrer variação somaclonal. Em vista disso, o presente trabalho teve como objetivo estabelecer um protocolo de regeneração para macieira, cultivar Gala.

\section{MATERIAL E MÉTODOS}

O experimento foi realizado no Laboratório de Cultura de Tecidos do Departamento de Botânica, na Universidade Federal de Pelotas-RS. As plantas utilizadas como fonte de explantes foram provenientes do cultivo in vitro, em fase de multiplicação, em meio contendo sais minerais de Murashige \& Skoog (MS) (1962), com nitrogênio reduzido a $3 / 4,100 \mathrm{mg} . \mathrm{L}^{-1}$ de mioinositol, 40 g. $\mathrm{L}^{-1}$ de sacarose, 6 g. $\mathrm{L}^{-1}$ de ágar, $1,0 \mathrm{mg} . \mathrm{L}^{-1} \mathrm{de}$

\footnotetext{
1 (Trabalho 104/2001). Recebido: 14/05/2001. Aceito para publicação: 13/09/2001.

2 Eng $^{\mathrm{a}}$ Agra $^{\mathrm{a}}$, Dra , Universidade Federal de Pelotas, Faculdade de Agronomia "Eliseu Maciel”, Departamento de Fitotecnia, Caixa Postal 354, 96.010900 - Pelotas, RS (marciaws@ufpel.tche.br).

3 Engo Agrº, Dr., Universidade Federal de Pelotas, Instituto de Biologia, Departamento de Botânica, Caixa Postal 354, $96.010-900$ - Pelotas, RS.
} 
Benzilaminopurina (BAP), com pH ajustado para 5,9 antes da colocação do ágar. Foram utilizados, como explantes, folhas inteiras escarificadas na nervura central, pedaços retangulares de folhas de aproximadamente $5 \mathrm{~mm}$ de largura e entrenós medindo entre 5 e $7 \mathrm{~mm}$ de comprimento, retirados de brotações em multiplicação após quatro semanas de repicagem. Para a regeneração das brotações, foram avaliados meios de cultura com diferentes composições, sendo que se utilizaram sais minerais e constituintes orgânicos de Murashige \& Skoog (MS) (1962) e ANA (Ácido naftalenoacético) a $0,2 \mathrm{mg} . \mathrm{L}^{-1}$ e a estes foram acrescentados os reguladores de crescimento BAP (Benzilaminopurina), TDZ (Thidiazuron), em diferentes concentrações $\left(0 ; 3,0 ; 4,0\right.$ e 5,0mg.L $\left.\mathrm{L}^{-1}\right)$. Os meios tiveram o pH ajustado para 5,8 e, após, adicionou-se 2,5 g.L $\mathrm{L}^{-1}$ de Gelrite.

Frascos contendo brotações com três semanas de cultivo in vitro foram colocados durante uma semana no escuro, em condições normais de temperatura de sala de crescimento. Outras brotações, também utilizadas como fonte de explantes, permaneceram quatro semanas em meio de multiplicação, em condições normais de sala de crescimento. Foram retirados folhas, segmentos foliares e entrenós e colocados nos diferentes meios de regeneração. Os explantes permaneceram três semanas em sala de crescimento, com temperatura de $23 \pm 1^{\circ} \mathrm{C}$ e ausência completa de luz. Posteriormente, foram transferidos para fotoperíodo de 16 horas e intensidade luminosa de $40 \mathrm{mmol} \mathrm{m}^{-2} \mathrm{~s}^{-}$ ${ }^{1}$, onde permaneceram durante dois meses. As variáveis analisadas, após este período, foram percentagem de explantes regenerados, número de brotações por explante e aparência dos mesmos, através de presença ou não de vitrificação. Todos os dados foram analisados através do pacote estatístico SANESTSistema de Análise Estatística- elaborado no Departamento de Matemática e Estatística da Universidade Federal de Pelotas (Zonta \& Machado, 1984).

O delineamento experimental adotado no experimento foi inteiramente casualizado, com fatorial $\mathrm{A}^{\prime} \mathrm{B}{ }^{\prime} \mathrm{C}$. O número de repetições foi três, sendo cada repetição um frasco com seis explantes. Os dados expressos em percentagem foram transformados segundo arco-seno raiz quadrada de (X/100), onde $\mathrm{X}$ significa o valor percentual obtido para cada variável. Para número médio de brotações, os dados foram transformados segundo raiz de $(X+0)$, onde $X$ significa o valor médio de brotações por explante regenerante.

\section{RESULTADOS E DISCUSSÃO}

Em relação à percentagem de explantes regenerados, foram significativos os fatores iluminação e a interação entre explante e meio de cultura, nas diferentes concentrações de BAP. Observou-se que aqueles explantes que foram retirados de brotações previamente submetidas ao escuro durante uma semana, tiveram uma maior percentagem de regeneração do que aqueles cujas brotações de origem permaneceram em condições normais de iluminação (Tabela 1). Estes resultados estão de acordo com Pawlicki \& Welander (1994) e Famiani et al. (1994), que conseguiram aumentar a taxa de regeneração de explantes de macieira, submetendo as brotações-mãe a um período de ausência de luz. Provavelmente, este estiolamento das brotações tenha provocado um maior teor de auxina endógena, já que as auxinas são sensíveis à luz, modificando, desta forma, o balanço auxina/citocinina e favorecendo a morfogênese.

A análise de regressão entre explante e meio mostrou um comportamento linear crescente, tanto para o explante folha como para o segmento foliar, conforme o aumento das concentrações de BAP (Figura 1-A). Entre os explantes testados, os que tiveram uma maior capacidade regenerativa foram folha inteira escarificada e segmento foliar. Estes resultados estão de acordo com Fortes \& Teixeira (1992), que obtiveram melhores resultados na organogênese de explantes foliares. Faria (1996), trabalhando com o porta-enxerto Marubakaido, obteve uma maior regeneração com a utilização de entrenós, enquanto folhas inteiras não regeneraram, porém foram os entrenós o tipo de explante que apresentou uma maior formação de calo $(99,5 \%)$. Quando se busca organogênese direta, este resultado não é interessante, pois existe possibilidade de ocorrer variação somaclonal se a regeneração for através de células não diferenciadas. No presente trabalho, não aconteceu regeneração com a utilização de entrenós, formando, na maioria deles, uma grande quantidade de calo na extremidade.

Em relação à melhor concentração de BAP (Fig.1-A), os resultados obtidos concordam com Yao et al. (1995), que obtiveram uma maior regeneração em macieira cultivar Royal Gala com a utilização de 5,0mg.L L $^{-1}$ de BAP no meio de cultura. Também Yepes \& Aldwinckle (1994) afirmam que a concentração de citocinina é um dos principais fatores que afetam a morfogênese, e obtiveram alta regeneração de cultivares de macieira, com variação entre genótipos, utilizando entre 5,0 e 7,0 mg.L $\mathrm{L}^{-1} \mathrm{de}$ BAP no meio de cultura.

Quanto ao número de brotações, houve interação entre explante, meio e iluminação. Conforme pode ser observado na Figura 1-B, o explante folha, quando as brotações foram mantidas na luz, teve um comportamento quadrático, onde foram formadas mais brotações $(2,13)$, em maiores concentrações de BAP $\left(5,0 \mathrm{mg} . \mathrm{L}^{-1}\right)$. Já o comportamento do explante folha, quando as brotações permaneceram uma semana no escuro, foi linear, atingindo seu máximo também a 5,0mg.L - $^{-1}$ de BAP. Em relação ao segmento foliar, o melhor resultado obtido foi no escuro com 3,0mg.L $\mathrm{L}^{-1}$ de BAP, diminuindo em concentrações maiores de BAP. Já o segmento na luz formou um maior número de brotações em maior concentração de BAP $\left(5,0 \mathrm{mg} \cdot \mathrm{L}^{-1}\right)$. Esses resultados mostram que, quando as brotações são submetidas a um período de uma semana de escuro, antes da retirada dos explantes, a necessidade de um fornecimento externo de BAP não é tão grande como quando são mantidas diretamente na luz, para formar o mesmo número de brotações. Também Famiani et al. (1994) obtiveram um maior número de brotações por explante em macieira, porta-enxerto M-26, quando submeteram estas a um período de escuro, dentro da mesma concentração de BAP no meio de cultura.

Com a utilização de TDZ no meio de cultura, a folha alcançou uma maior percentagem de regeneração $(85,57 \%)$ na concentração de 4,0mg. $\mathrm{L}^{-1}$. Também o segmento foliar teve a maior regeneração $(77,11 \%$ ) nesta concentração (Figura 2-A), e os entrenós não regeneraram. Segundo Chevreau et al. (1989), o TDZ é utilizado com sucesso na regeneração de várias espécies lenhosas. Autores como De Bondt et al. (1996) obtiveram um melhor resultado com 5,0mg.L $\mathrm{L}^{-1}$ de TDZ no meio de cultura, para a regeneração de explantes foliares de macieira, cultivar Jonagold. 
TABELA 1 - Percentagem de regeneração de explantes de macieira, cultivar Gala, em meio de cultura com BAP, em diferentes regimes de luz. Pelotas-RS, 2000

\begin{tabular}{lc}
\hline \multicolumn{1}{c}{ Regimes de luz } & \% Regeneração \\
\hline Escuro & $48,00 \mathrm{a}$ \\
Luz & $26,54 \mathrm{~b}$ \\
\hline
\end{tabular}

Médias seguidas de mesma letra, nas colunas, não diferem entre si, pelo teste de Duncan $(\alpha 0,05)$

A

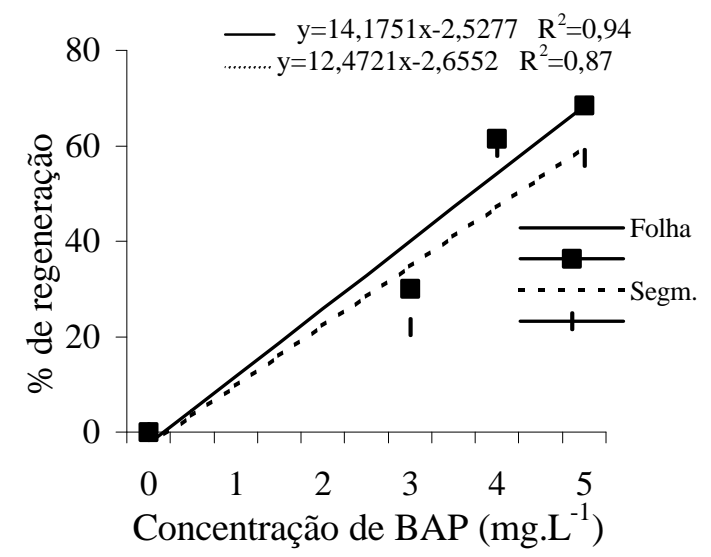

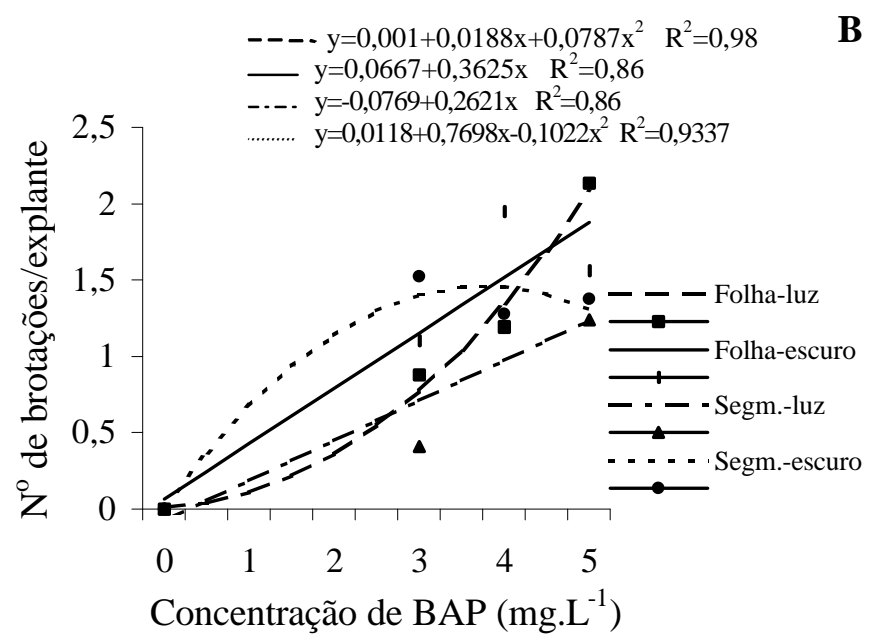

FIGURA 1- A) Percentagem de regeneração de brotações de macieira, cultivar Gala, em meio de cultura com diferentes concentrações de BAP. Pelotas-RS, 2000.

B) Número de brotações formadas em diferentes tipos de explantes de macieira, cultivar Gala, em meios de cultura com diferentes concentrações de BAP e diferentes regimes de luz. Pelotas-RS, 2000.

Este regulador tem sido utilizado para a formação de brotações em várias plantas, especialmente as lenhosas, mostrando-se mais efetivo que outros tipos de citocinina, como BAP e Cinetina e em concentrações extremamente baixas (Nayak et al., 1997). Shibli \& Smith (1996) conseguiram 75\% de regeneração em explantes foliares de mirtilo com a utilização de $0,6 \mathrm{mg} . \mathrm{L}^{-1}$ de TDZ no meio de cultura. Também Sarwar \& Skirvin (1997), utilizando TDZ em concentrações de 0,44 e $0,66 \mathrm{mg} . \mathrm{L}^{-1}$, regeneraram explantes foliares de macieira, cultivares McIntosh, Macspur e Wijcik.

Neste experimento, o que se pode observar em relação ao efeito do TDZ é que, embora a percentagem de regeneração tenha sido alta nas maiores concentrações $\left(4,0\right.$ e 5,0mg. $\left.\mathrm{L}^{-1}\right)$, os explantes apresentavam vitrificação praticamente total. Estes resultados concordam com Nieuwkerk \& Zimmerman (1986), que afirmam que alta concentração de TDZ causa necrose dos tecidos, vitrificação e crescimento anormal da folha.

Conforme Figura 2-B, pode-se observar que, quando as brotações foram mantidas na luz, o comportamento da percentagem de regeneração de explantes foi de acordo com um modelo de regressão quadrática, atingindo uma maior percentagem em concentrações intermediárias de TDZ, vindo a diminuir em concentrações maiores. Já quando as brotações foram submetidas a uma semana de escuro, o comportamento foi de acordo com um modelo de regressão linear, regenerando mais $(54,29 \%)$ em maior concentração de TDZ. Na luz, a necessidade de TDZ, até um certo ponto, foi menor para regenerar brotações, do que no escuro. Este resultado discorda dos de Shibli \& Smith (1996), que obtiveram um significativo aumento na percentagem de regeneração e no número de brotações, formadas com tratamento no escuro, de explantes foliares de mirtilo. Com a utilização de concentrações entre 0,2 e 0,4 mg.L ${ }^{-1}$ de TDZ, a préincubação no escuro mais que dobrou a percentagem de regeneração, comparando com os tratamentos mantidos sob iluminação normal.

Em relação ao número de brotações, observa-se (Figura 2-C) que, nos explantes folha retirados de brotações mantidas na luz, formou-se um maior número de brotos do que naqueles submetidos a uma semana de escuro, alcançando seu máximo a 4,0mg.L -1 $^{-1}$ e TDZ, ou seja, 2,59 brotos por explante, contra 1,83 brotos no explante submetido ao escuro. O explante segmento foliar formou o máximo de brotações em meio de cultura contendo $3,0 \mathrm{mg} . \mathrm{L}^{-1}$ de TDZ, tanto na luz $(1,71)$ quanto no escuro $(1,70)$. Nestes resultados, observa-se que a ausência de luz também não favoreceu o número de brotações por explante.

A maioria das brotações formadas com a utilização de TDZ eram muito pequenas, agrupadas e vitrificadas. Segundo Kim et al. (1997), com a utilização de TDZ, o número de brotações formadas é bastante grande em maiores concentrações, como 5,0 e $10,0 \mathrm{mg} . \mathrm{L}^{-1}$, mas com um alongamento bastante pequeno. Estes autores conseguiram alta frequiência na indução de brotações em plantas lenhosas com a utilização de $1,0 \mathrm{mg} . \mathrm{L}^{-1} \mathrm{de}$ TDZ. 

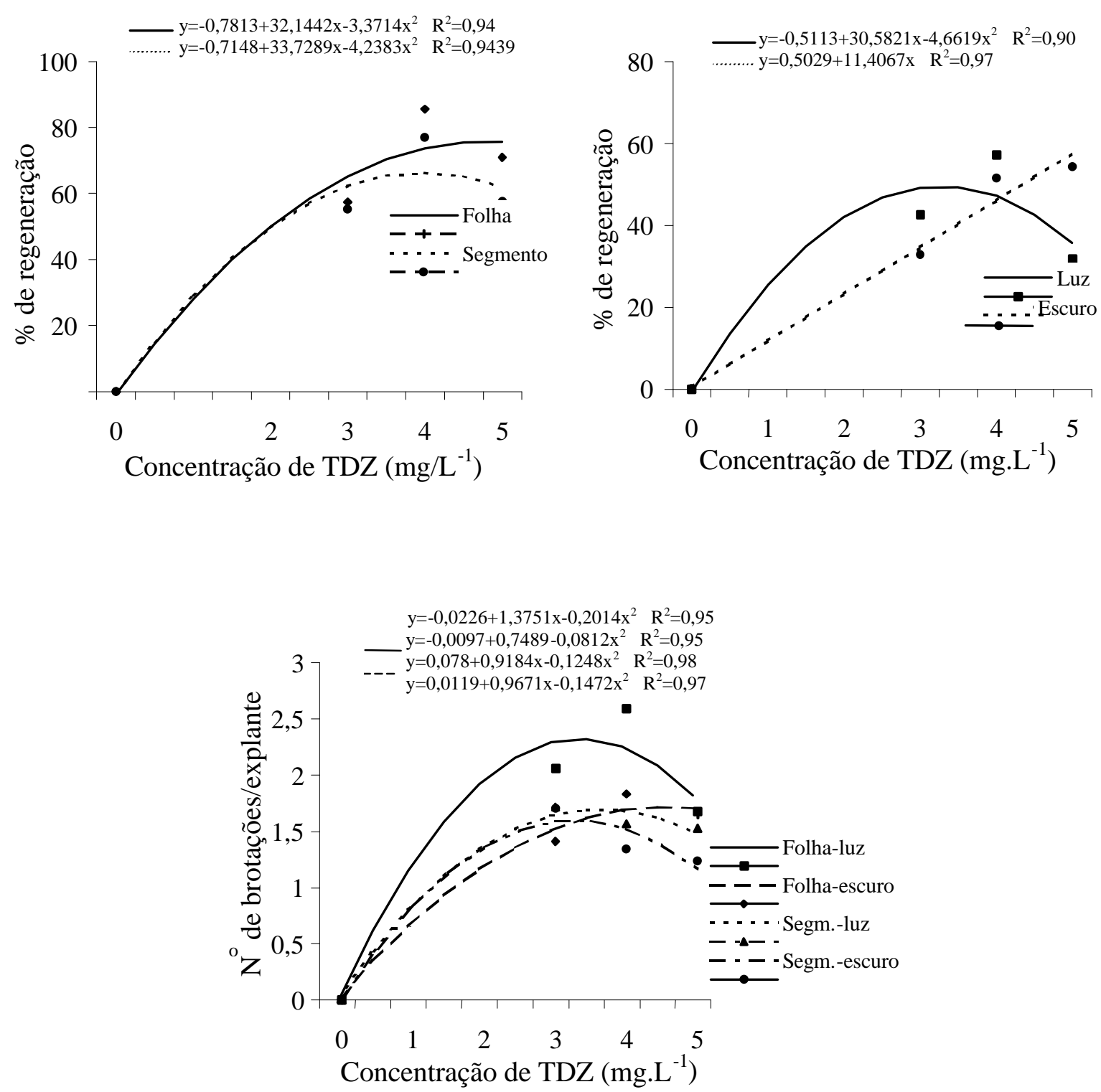

FIGURA 2 - A) Percentagem de regeneração de explantes de macieira, cultivar Gala, em meios de cultura com diferentes concentrações de TDZ. Pelotas-RS, 2000.

B) Percentagem de regeneração de explantes de macieira, cultivar Gala, submetidos a meios de cultura com diferentes concentrações de TDZ e regimes de luz. Pelotas-RS, 2000.

C) Número de brotações formadas em diferentes tipos de explantes de macieira, cultivar Gala, em meios de cultura com diferentes concentrações de TDZ e regimes de luz. Pelotas-RS, 2000.

\section{CONCLUSÕES}

1- A colocação das brotações no escuro aumenta a taxa de regeneração.

2- Os explantes folha e segmento foliar apresentam maior potencial regenerativo que entrenós.

3- BAP nas concentrações de 4,0 a 5,0 mg. $\mathrm{L}^{-1}$ induz a uma maior regeneração de brotações.

4- Explantes retirados de brotações submetidas ao escuro necessitam de uma menor concentração de BAP, para formar o mesmo número de brotações, do que aqueles mantidos na luz. 5- TDZ em altas concentrações $\left(4,0\right.$ e $\left.5,0 \mathrm{mg} \cdot \mathrm{L}^{-1}\right)$ induz a vitrificação.

\section{REFERÊNCIAS BIBLIOGRÁFICAS}

CHEVREAU, E.; SKIRVIN, R.M.; ABU-QAOUD, H.A.; KORBAN, S.S.; SULLIVAN, J.G. Adventitious shoot regeneration from leaf tissue of three pear (Pyrus sp.) cultivars in vitro. Plant Cell Reports, Berlin, v. 7, p. 688-691, 1989.

DE BONDT, A.; EGGERMONT, K.; PENNINCKX, I.; GODERIS, I.; BROEKAERT, W.F. Agrobacterium-mediated transformation of apple (Malus domestica Borkh): and assessment of factors affecting regeneration of transgenic plants. Plant Cell Reports, Berlin, v. 15, p. 549-554, 1996. 
FAMIANI, F.; FERRADINI, N.; STAFFOLANI, P.; STANDARDI, A. Effect of leaf excision, time and age, BA concentration and dark treatments on "in vitro" shoot regeneration of M-26 apple rootstock. Journal of Horticultural Science, Ashford, v. 69, n. 4, p. 679-685, 1994.

FARIA, J.T.C. Calogênese e organogênese "in vitro" em portaenxerto de macieira cv. Marubakaido. 1996, 50 p. Dissertação (Mestrado em Fitomelhoramento)-Faculdade de Agronomia Eliseu Maciel, Universidade Federal de Pelotas.

FORTES, G. R. L.; TEIXEIRA, S. L. Calogênese e organogênese de material somático de macieira (Malus domestica, Borkh.). In: CONGRESSO IBERO-AMERICANO, 1, CONGRESSOLATINOAMERICANO, 5, CONGRESSO NACIONAL DE HORTICULTURA, 4, Montevidéu, p. 21, 1992.

KIM, M.S.; SCHUMANN, C.M. ; KLOPFENSTEIN, N.B. Effects of thidiazuron and benzyladenine on axillary shoot proliferation of three green ash (Fraxinus pennsylvanica Marsh.) clones. Plant Cell, Tissue and Organ Culture, Dordrecht, v. 48, p. 4552, 1997.

NAYAK, N.R.; PATNAIK, S.; RATH, S.P. Direct shoot regeneration from foliar explante of and epiphytic orthid, Acampe traemorsa (Roxb) Blatter and McCann. Plant Cell Reports, Berlin, v. 16, p. 583-586, 1997.

NIEUWKERK, J.P.V.; ZIMMERMAN, R.H. Thidiazuron stimulation of apple shoot proliferation in vitro. HortScience, Alexandria, v. 21, n. 3, p. 516-518, 1986.

PAWLICKI, N.; WELANDER, M. Adventitious shoot regeneration from leaf segments of in vitro cultured shoots of the apple rootstock Jork 9. Journal of Horticultural Science, Ashford, v. 69, n. 4, p. 687-695, 1994.

RAO, C.D.; GOH, C.J.; KUMAR, P.P. High frequency adventitious shoot regeneration from excised leaves of Pawlownia spp. cultured in vitro. Plant Cell Reports, Berlin, v. 16, p. 204-209, 1996.

SARWAR, M.; SKIRVIN, R.M. Effect of thidiazuron and 6benzylaminopurine on adventitious shoot regeneration from leaves of three strains of McIntosh apple (Mallus domestica Borkh.) in vitro. Scientia Horticulturae, Amsterdam, v. 68, p. 95 100, 1997.

SHIBLI, R.A.; SMITH, M.A.L. Direct shoot regeneration from Vaccinium pahalae (ohelo) and V. myrtillus (Bilberry) leaf explants. HortScience, Alexandria, v. 31, n. 7, p. 1225-1228, 1996.

TZFIRA, T.; JENSEN, C.S.; VAINSTEIN, A.; ALTMAN, A. Transformation and regeneration of transgenic aspen plants via shoot formation from stem explants. Physiologia Plantarum, Copenhagen, v. 99, p. 554-561, 1997.

YAO, J.L.; COHEN, D.; ATKINSON, R.; RICHARDSON, K.; MORRIS, B. Regeneration of transgenic plants from the commercial apple cultivar Royal Gala. Plant Cell Reports, Berlin, v. 14, n. 7, p. $407-412,1995$.

YEPES, L.M.; ALDWINCKLE, H.S. Factors that affect leaf regeneration efficiency in apple, and effect of antibiotics in morphogenesis. Plant Cell, Tissue and Organ Culture, Dordrecht v. 37, n. 3, p. 257-269, 1994. 